\title{
BMJ Open Scaling-up social needs screening in practice: a retrospective, cross-sectional analysis of data from electronic health records from Bronx county, New York, USA
}

\author{
Kevin P Fiori (D) , ${ }^{1,2,3}$ Caroline G Heller, ${ }^{1}$ Anna Flattau, ${ }^{3}$ \\ Nicole R Harris-Hollingsworth, ${ }^{3,4}$ Amanda Parsons, ${ }^{5}$ Michael L Rinke, ${ }^{2,6}$ \\ Earle Chambers, ${ }^{3}$ Sybil Hodgson, ${ }^{3,6}$ Tashi Chodon, ${ }^{7}$ Andrew D Racine ${ }^{2,6}$
}

To cite: Fiori KP, Heller CG, Flattau A, et al. Scaling-up social needs screening in practice: a retrospective, cross-sectional analysis of data from electronic health records from Bronx county, New York, USA. BMJ Open 2021;11:e053633. doi:10.1136/ bmjopen-2021-053633

- Prepublication history and additional supplemental material for this paper are available online. To view these files, please visit the journal online (http://dx.doi.org/10.1136/ bmjopen-2021-053633).

Received 19 May 2021 Accepted 13 September 2021

Check for updates

(C) Author(s) (or their employer(s)) 2021. Re-use permitted under CC BY-NC. No commercial re-use. See rights and permissions. Published by BMJ.

For numbered affiliations see end of article.

Correspondence to

Dr Kevin P Fiori;

kfiori@montefiore.org

\section{ABSTRACT}

Objectives There has been renewed focus on health systems integrating social care to improve health outcomes with relatively less related research focusing on 'real-world' practice. This study describes a health system's experience from 2018 to 2020, following the successful pilot in 2017, to scale social needs screening of patients within a large urban primary care ambulatory network.

Setting Academic medical centre with an ambulatory network of 18 primary care practices located in an urban county in New York City (USA).

Participants This retrospective, cross-sectional study used electronic health records of 244764 patients who had a clinical visit between 10 April 2018 and 8 December 2019 across any one of 18 primary care practices.

Methods We organised measures using the RE-AIM framework domains of reach and adoption to ascertain the number of patients who were screened and the number of providers who adopted screening and associated documentation, respectively. We used descriptive statistics to summarise factors comparing patients screened versus those not screened, the prevalence of social needs screening and adoption across 18 practices.

Results Between April 2018 and December 2019, 53 093 patients were screened for social needs, representing approximately $21.7 \%$ of the patients seen. Almost one-fifth (19.6\%) of patients reported at least one unmet social need. The percentage of screened patients varied by both practice location (range 1.6\%-81.6\%) and specialty within practices. $51.8 \%$ of providers $(n=1316)$ screened at least one patient.

Conclusions These findings demonstrate both the potential and challenges of integrating social care in practice. We observed significant variability in uptake across the health system. More research is needed to better understand factors driving adoption and may include harmonising workflows, establishing unified targets and using data to drive improvement.
Strengths and limitations of this study

- Large health system's experience with scaling social need assessments (53 093 patients) across 18 clinical practices.

- Description of associated challenges related to 'realworld' implementation that need to be considered for scale.

- Evaluation highlighted that providing clinical teams with the appropriate tools such as electronic health tools and social service navigation or linkage is required but not sufficient for uptake.

- Significant heterogeneity and variation in adoption was observed that was not adequately explained based on the data available.

- Data were cross-sectional and sourced from electronic health record which may be limiting both in terms of temporality and completeness.

\section{BACKGROUND}

Medical societies, health systems and providers have voiced support for addressing upstream factors of health, or social determinants of health, by integrating social care activities in healthcare. ${ }^{1}$ In 2019, the National Academy of Sciences, Engineering and Medicine published a report outlining guidance on social care integration in the delivery of healthcare. ${ }^{2}$ Key activities to increase health system awareness at both the individual level (adjustment and assistance) and community level (alignment and advocacy) were put forth and described in this report. Assistance activities, defined as programmes that connect patients to social services, have been highlighted by a growing evidence base of effective pilot programmes and randomised controlled trials. ${ }^{3-7}$ However, most studies focusing on social care integration are of low 
quality and/or are focused on a limited patient population (eg, paediatrics) or one social need category (eg, food insecurity). ${ }^{8}$ It is less clear whether such pilots and programmes conducted in a research context can be scaled or are effective in practice, respectively. To date, less research has been conducted on health systems efforts to scale and descriptions of the challenges related to 'realworld' implementation of social integration initiatives. ${ }^{9-11}$

This study's objective was to describe a health system's experience with implementing assistance initiatives within a large urban primary care ambulatory network in a nonresearch context using electronic health record (EHR) enhancements, audit and feedback activities through data reports, quality improvement collaboratives and adaptive workflows. ${ }^{12}$ To our knowledge, it is the first 'real-world' case description of a health system's experience scaling assistance activities. A well-established implementation science framework, RE-AIM ${ }^{13}$ was adapted to evaluate adoption and utilisation of screening tool in clinical practices in the first 20 months of the initiative. The authors' hypothesis was that strategies that provide resources, tools and data to support social needs assessments in clinical care would lead to high levels of adoption of screening for unmet social needs in clinical care.

\section{METHODS}

\section{Setting}

Almost 50 years after the founding of the a Residency Programme in Social Medicine, ${ }^{14}$ the health system embarked in 2017 on a broad initiative to systematically identify and assist patients with unmet social needs within its primary care network that serves over 460000 New Yorkers. ${ }^{15} 16$ This assistance initiative included a systemwide approach to increase screening and referral for social needs through (1) the use of an embedded cadre of social workers and practice-based community health workers (CHWs), (2) the development of an online social service directory to facilitate referrals, (3) enhanced clinical note documentation and (4) robust systems support for ongoing performance improvement. Results from this initiative have been published previously on social risk prevalence, ${ }^{15}$ the association of clinical diagnoses and no-show visits with unmet social needs,${ }^{14}$ and clinical outcomes. ${ }^{17}$ This study describes our health system's real-world attempt to implement social needs screening at scale.

\section{Intervention description}

In 2017, a multidisciplinary team composed of clinical providers, administrators, social workers and communitybased partners met to discuss implementing social needs assessments across a network of 18 primary care practices. This intervention focused on establishing the following for clinical teams starting in April 2018: (1) a standardised social needs screening tool integrated within the EHR, (2) adaptive practice-based workflows including linkage to social service referral supports and (3) integration of the activities into quality improvement processes including data support. The decisions on how to use these tools was determined by clinical teams at each practice. There were commonalities across the health system that included the EHR screening tool interface, self-administered use of the tool using a paper form that had to be entered into the EHR, translations of the screener, data reporting and performance improvement methodologies and support. There was variation in how each clinical team chose patients to screen and at what frequency, the role and engagement of staff members and the referral pathways. Patients and/or families reserved the right to decline both screening and/or additional referral support if a need was identified.

The social needs screening tool was initially developed and tested over a brief pilot period for feasibility and acceptance at selected practices prior to April 2018. A finalised version was adapted from the Health Leads toolkit $^{18}$ and embedded within our health system's EHR in 2018 (online supplemental file 1). Selection criteria for items included in the screening tool were that they needed to be succinct, relevant to patient needs, integrated into existing workflows, actionable and, where possible, previously validated. The final screener was provided both in a paper version translated in nine other languages and integrated into the EHR to allow tracking. Social need categories in the final 10-item screener included: housing insecurity and quality, food insecurity, utilities, health transportation, medications, child or elderly care, legal services, family stress and safety (online supplemental file 1).

Given a lack of evidence-based guidelines on which patients should be screened and at what frequency, clinical teams were encouraged to adapt recommended workflows based on practice-level considerations such as volume and staff structure. Some practices chose to screen new patients only, while others chose subsets of patients, including those seen by particular providers or those deemed to be at higher risk, for example, pregnant women (online supplemental file 2). While there was variability in selecting the populations to screen, practices were encouraged to follow certain guidelines, including giving the patient a paper-copy of the screener in the appropriate language to be self-administered, and having clinical staff enter the results in the EHR prior to commencing the visit with the primary provider. This ensures that providers were able to review the results with the patient and determine what follow-up, if any, needed to occur.

The multidisciplinary planning team supported clinical teams in adapting both screening and referral workflows to consider contextual factors specific to each practice and clinical team. Practices were provided with recommendations, but the decision on what patient population to screen and at what frequency was left to each clinical team to decide. The planning team decided to allow such flexibility in these workflows based on the distinct contexts of each practice location and clinical teams' 
perceptions of feasibility. Providers had several options for connecting patients with social needs to services. Some practices included social workers and/or CHWs within their care teams, either full time or part time; others had no such support. All practices had access to an online social service resource directory ${ }^{19}$ that could be filtered based on social need categories, patient preferences such as location, hours of operation, etc. Each practice developed both specific screening and referral workflows for patients who identified an unmet social need(s) that involved referrals to CHWs, social work and/ or utilisation of online resource directory based on each practice's context.

There was a deliberate effort to integrate these activities with the primary care network's ongoing performance improvement structures, including performance coaches and network-wide learning collaborative meetings that were leveraged to discuss best practices. The ambulatory network analytics team provided monthly reports summarising screening data for clinical and administrative leadership at practices.

\section{Study population}

This retrospective, cross-sectional study uses data extracted from the EHR to assess the utilisation of the social needs screening tool across 18 participating ambulatory sites. Data for this study come from outpatient paediatric, internal medicine and family medicine practices from 10 April 2018 to 8 December 2019 and was extracted using Looking Glass Clinical Analytics V.4.4.2 (Streamline Health, Atlanta, Georgia, USA).$^{20}$ Patients were eligible for inclusion in the analysis if they had at least one outpatient visit, either a routine follow-up or sick visit, at any one of the 18 ambulatory practices within the specified time frame.

\section{Measures}

We organised both process and outcomes measures using the RE-AIM (Reach, Effectiveness, Adoption, Implementation, Maintenance) implementation framework $^{13}$ domains of reach and adoption to ascertain the number of patients who participated in screening and the number of providers who initiated the screening and documentation elements of the intervention, respectively. ${ }^{21}$ The reach measure was whether an active patient was screened for social needs at least one time during the time period (dichotomised $0=$ not screened; $1=$ screened). This measure was defined as whether social needs screener results had been entered within a documented patient note in the EHR. An additional adoption measures focused on clinical team behaviours the measured the proportion of providers who ever used the screening tool during a clinical encounter. Any provider seeing $\geq 1$ patient during the time frame was included in the analysis. Positive screens were defined as having 1 or more of the 10-item screening checks marked as 'yes'. Patients who refused screening as documented in EHR were excluded from the analysis.

\section{Covariates}

Covariates included patient-level and practice-level characteristics. Patient-level characteristics comprised age (categorised: $0-5 ; 6-11 ; 12-20 ; 21-34 ; 35-49 ; 50-64 ; \geq 65$ years), sex, race/ethnicity (Hispanic, non-Hispanic black, non-Hispanic white, non-Hispanic Asian/Pacific Islander, non-Hispanic American Indian/Alaskan native and a missing indicator), health insurance at the screening visit (Medicaid, Medicare, Commercial and a missing indicator), the patient's preferred language (English, Spanish, other and a missing indicator), whether the respondent lived in New York City public housing, and area-level poverty status. In order to identify public housing status and area-level poverty, patients with New York State addresses were geocoded using the New York State Street and Address Composite geocoding services tool. ${ }^{22}$ After $98.2 \%$ of patients were successfully geocoded, patients were assigned to their Census block group using a spatial join and then joined to 2014-2018 American Community Survey household poverty data at the block group level. ${ }^{23}$ Patients were identified as residing in public housing if their addresses geocoded to tax lots associated with public housing. Practice-level characteristics included physician specialty (categorised as paediatrics; family medicine; internal medicine) and the associated quality improvement rating by specialty (internal health system measure that places practices in quintiles based on overall performance on key measures), practice type (categorised as a teaching site for resident physicians, a neighbourhood site or a group site), the number of active providers (categorised as small, medium and large terciles), CHW resource status (categorised as none, having a CHW present and having a CHW devoted full time to supporting social needs referrals present) and having Federally Qualified Health Center status.

\section{Analysis}

We used descriptive statistics to summarise demographic factors comparing patients screened versus those not screened. The prevalence of social needs screening among the active patient population was estimated for each population subgroup and by each clinical specialty. The proportion of active providers screening for social needs was also estimated overall, by practice location and categorised by number of screens conducted. Statistical analyses were performed using Stata V.16.0 (StataCorp) and mapping used ArcGIS V.10.3.1 (ESRI, Redlands, California, USA).

\section{Patient and public involvement}

Though the initiative engaged multiple stakeholders both internal and external to our health system, these analyses were conducted with a team internal to the health system. These findings will be disseminated to key partners to inform next steps in the future.

\section{RESULTS}

Between 10 April 2018 and 8 December 2019, 244 764 unique patients visited participating primary care 
practices within our network, with 53093 unique patients screened for social needs at least once during the time period, representing approximately $21.7 \%$ of the patients seen by our primary care network. Of these, $19.6 \%$ of patients had at least one social need identified using the screening tool. We summarised demographic factors comparing the screened population to the not screened population (table 1) across the practices. Those who were screened were younger (median age 30.3 years compared with 35.3 years), more likely to be Hispanic and to have Spanish as their preferred language. Screened patients were also more likely to be on Medicaid, reside in public housing and live in higher poverty areas. Patients who received care at a practice with a CHW focusing on social service support were more likely to be screened, $28.8 \%$, vs those practices without a CHW, $15.3 \%$, or with a CHW present but not focused on social service support, $12.7 \%$. Percentage of ever screened patients varied by both practice location and specialty within practices (range 1.6\%$81.6 \%$ ). Overall, $26.2 \%$ of active paediatrics patients were screened in comparison to $19.0 \%$ of family medicine patients and $19.9 \%$ of internal medicine patients (figure 1).

As summarised in figure 2, almost half of active providers $(48.2 \%)$ did not use the screen during any patient encounter during the study time frame. The screening frequency varied among providers who used the screen $(\mathrm{n}=694)$ with $12.8 \%$ (168) providers conducting between 1 and 5 screens over the period and $12.9 \% \quad(n=170)$ conducting more than 53 screens. Paediatric providers were the largest proportion of active providers screening $(54.5 \%)$, followed by internal medicine $(49.2 \%)$ and family medicine providers $(48.5 \%)$. At the practice level, the percentage of active providers screening for social needs ranged from $3.1 \%$ to $100 \%$ (denominator for latter percentage: $\mathrm{n}=1$ ).

\section{DISCUSSION}

This study describes a large urban health system's real-world efforts to integrate social needs screening across 18 distinct primary care practices and associated implementation outcomes related to patient population reached and adoption by providers. To our knowledge, this is the first case description of a large academic medical centre's experience scaling social needs screening within a primary care network. We observed a meaningful percentage of patients screened, 21.7\% ( $\mathrm{n}=53$ 093), though the proportion of the patient population screened ranged from $1.6 \%$ to $81.6 \%$ across the 18 practices and also varied among clinical teams at the same practice location, with 5 clinical teams disproportionately screening greater than $50 \%$ of their patients. Some heterogeneity may be explained by our health system's initial decision to allow clinical teams to determine which patient populations to screen and at what frequency. For example, the paediatric clinical team at one practice (C6) had a goal of screening each paediatric patient annually resulting in $82 \%$ of its active patient population screened. In contrast, the internal medicine team within the same practice location aimed to only screen a subset of new patients resulting in $9 \%$ of its active patient population screened. Overall, approximately $51.8 \%$ of providers at participating sites adopted use of the social screen during at least one clinical encounter with a wide distribution of screening utilisation. The data also suggest that most providers did not use the screen routinely, likely driving lower active patient screening proportions at most practices. One important factor that was associated with higher rates of screening was a CHW present at the practice that specifically focused on social needs resource support, this finding may further support the importance of having resources to help patients as a driver of screening adoption. These important findings demonstrate both the potential and challenges of scaling system-wide efforts and provide generalisable implementation considerations that may inform learning and performance improvement within our health system and others.

Though this study describes an urban, academic medical systems attempt to scale social needs screening across its primary care network in practice, these findings are consistent with reports from a community health network and expanded pilot in paediatrics $^{24-26}$ that found challenges and heterogeneity of adoption despite providing tools to support social needs screening in primary care. ${ }^{27}$ In a descriptive study that summarised a large network of community health centres, there was clear heterogeneity of screening uptake ${ }^{24}$ with 4 out of 71 community health centres accounting for over half $(55 \%)$ of the screeners conducted and with only $2 \%$ of the patient population screened during study period. ${ }^{24}$ Both studies suggest that simply providing tools, EHR integrated screening and referral resources to support social needs screening is required but not sufficient to drive uptake. Furthermore, the ambiguities and lack of clear evidence-based guidance around which patients should be screened seems to pose similar barriers to adoption and may explain variation.

There are several important limitations in this study. First, there are likely multiple practice-based factors specific to each clinical team that we could not capture in this study as it relied on EHR data. In addition, EHR data entry can be unreliable as it is not designed for research, and it is possible that we under-reported social needs screening uptake and/or assessments if practices used the paper-based screening tool or enhanced social historiesonly format. Second, we did not assess screening fidelity rates, specifically the extent to which practices screened their original target populations. It was not possible to assess whether and to what extent clinical teams carried out screening as planned due to limitations in extracting the appropriate denominator from the EHR. Additional data 
Table 1 Summary of characteristics comparing active ${ }^{\star}$ patients who were screened or not screened for social needs between 10 April 2018 and 8 December 2019 ( $n=244$ 764)

\begin{tabular}{|c|c|c|c|c|c|}
\hline & & $\mathbf{n}$ & Screening \% & $95 \% \mathrm{Cl}$ & $\mathrm{P}$ value \\
\hline \multirow[t]{7}{*}{ Age } & $<0-5$ years & 32038 & 25.98 & 25.50 to 26.47 & $<0.0001$ \\
\hline & $6-11$ years & 26268 & 23.60 & 23.08 to 24.11 & \\
\hline & $12-17$ years & 23536 & 21.91 & 21.38 to 22.44 & \\
\hline & $18-24$ years & 18283 & 23.33 & 22.71 to 23.94 & \\
\hline & 25-44 years & 47263 & 19.61 & 19.25 to 19.97 & \\
\hline & $45-64$ years & 60183 & 18.64 & 18.33 to 18.96 & \\
\hline & $\geq 65$ years & 37193 & 23.29 & 22.86 to 23.72 & \\
\hline \multirow[t]{2}{*}{ Sex } & Male & 100395 & 21.65 & 21.39 to 21.90 & 0.6667 \\
\hline & Female & 144369 & 21.72 & 21.51 to 21.93 & \\
\hline \multirow[t]{5}{*}{ Race/ethnicity } & Hispanic & 88615 & 23.27 & 22.99 to 23.55 & $<0.0001$ \\
\hline & $\mathrm{NH}$ black & 69593 & 20.77 & 20.47 to 21.07 & \\
\hline & $\mathrm{NH}$ white & 14053 & 14.47 & 13.89 to 15.06 & \\
\hline & $\mathrm{NH}$ API & 5412 & 18.70 & 17.66 to 19.74 & \\
\hline & NH AIAN & 966 & 16.15 & 13.83 to 18.47 & \\
\hline \multirow[t]{3}{*}{ Language } & English & 197801 & 21.37 & 21.19 to 21.55 & $<0.0001$ \\
\hline & Spanish & 35458 & 23.51 & 23.07 to 23.95 & \\
\hline & Other & 7630 & 17.51 & 16.66 to 18.36 & \\
\hline \multirow[t]{3}{*}{ Insurance } & Commercial & 83242 & 20.46 & 20.19 to 20.74 & $<0.0001$ \\
\hline & Medicaid & 102333 & 23.71 & 23.45 to 23.98 & \\
\hline & Medicare & 39755 & 22.46 & 22.05 to 22.87 & \\
\hline \multirow[t]{2}{*}{ FQHC } & No & 158454 & 18.60 & 18.41 to 18.79 & $<0.0001$ \\
\hline & Yes & 86310 & 27.37 & 27.07 to 27.66 & \\
\hline \multirow[t]{2}{*}{ NYC Public Housing } & No & 186648 & 22.63 & 22.44 to 22.82 & $<0.0001$ \\
\hline & Yes & 21903 & 26.71 & 26.12 to 27.29 & \\
\hline \multirow[t]{5}{*}{ Poverty category } & Q1 & 47049 & 18.64 & 18.28 to 18.99 & $<0.0001$ \\
\hline & Q2 & 46917 & 19.65 & 19.29 to 20.01 & \\
\hline & Q3 & 47100 & 22.29 & 21.91 to 22.66 & \\
\hline & Q4 & 47156 & 23.59 & 23.20 to 23.97 & \\
\hline & Q5 & 47076 & 24.55 & 24.16 to 24.94 & \\
\hline \multirow[t]{3}{*}{ Specialty type } & Paediatrics & 79377 & 26.25 & 25.94 to 26.56 & $<0.0001$ \\
\hline & Family medicine & 39598 & 18.31 & 17.93 to 18.69 & \\
\hline & Internal medicine & 125789 & 19.88 & 19.66 to 20.10 & \\
\hline \multirow[t]{3}{*}{ Site type } & Group & 115804 & 18.01 & 17.79 to 18.23 & $<0.0001$ \\
\hline & Neighbourhood & 31671 & 29.58 & 29.07 to 30.08 & \\
\hline & Teaching & 97289 & 23.50 & 23.24 to 23.77 & \\
\hline \multirow[t]{3}{*}{ Active provider tercile } & Small & 86291 & 22.21 & 21.93 to 22.48 & $<0.0001$ \\
\hline & Medium & 82072 & 22.83 & 22.54 to 23.11 & \\
\hline & Large & 76401 & 19.89 & 19.61 to 20.17 & \\
\hline \multirow{3}{*}{$\begin{array}{l}\mathrm{CHW} \text { at practice providing } \\
\text { social service referrals }\end{array}$} & None & 69869 & 15.24 & 14.97 to 15.51 & $<0.0001$ \\
\hline & Yes & 49019 & 12.65 & 12.35 to 12.94 & \\
\hline & Yes, SDH focused & 125876 & 28.80 & 28.54 to 29.05 & \\
\hline
\end{tabular}

*Active patients: this included patients who presented for care at least once during time period. this includes $1.8 \%$ of active patient population that refused.

AIAN, American Indian/Alaska Native; API, Asian Pacific Islander; CHW, community health worker; FHQC, federally qualified health centre; $\mathrm{NH}$, non-Hispanic; NYC, New York City; SDH, social determinant of health. 


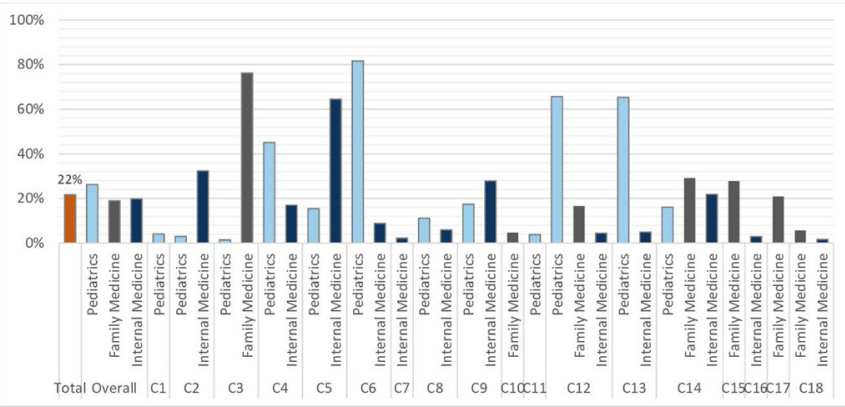

Figure 1 Proportion of active* patients $(n=244764)$ screened for unmet social needs from 10 April 2018 to 8 December 2019 by clinical practice location (C\#) and primary care provider specialty (within same clinical location).

analysis regarding screening fidelity are planned to better assess performance. Next, our measures of proportion of providers using the screener may be limited in that we are not able to ascertain whether another member of the clinical team (ie, nurse) ultimately conducted the screen, and therefore this may not be an ideal measure. Last, these data are cross-sectional and the social needs identified do not capture longitudinal trends in prevalence.

Notwithstanding these limitations, this evaluation proved to be valuable in our health systems' evolving effort to become more aware of and subsequently develop strategies to address social needs of patients. Next steps should include additional data collection (qualitative interviews and surveys) to understand factors that influence adoption of social needs screening and referral processes. This experience to date has reinforced the need to harmonise core workflow elements across clinical setting, such as target populations and clinical team roles, while still allowing for some variability and adaptation at the practice level. We have developed a new health system objective

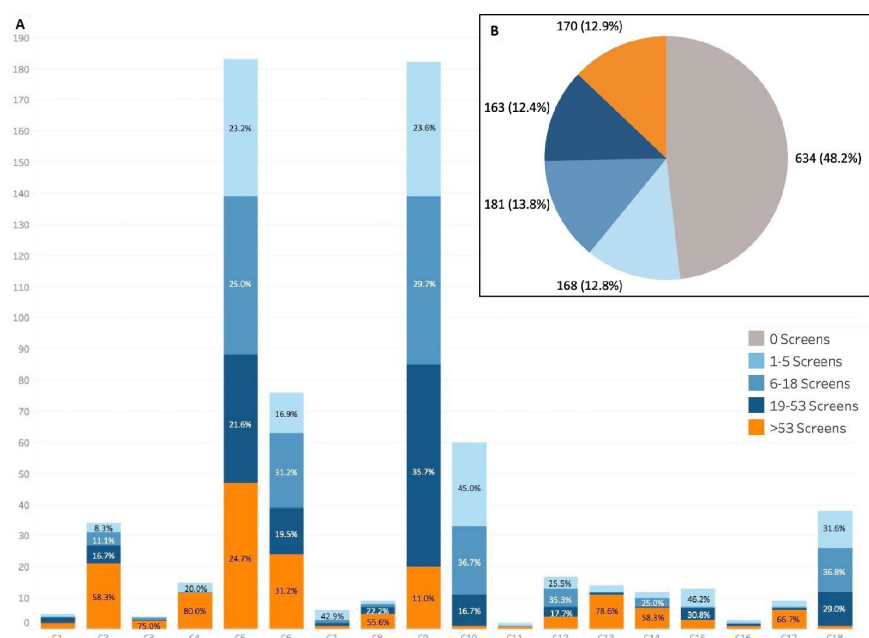

Figure 2 Key adoption measures. (A) Distribution of screening frequency categorised by active providers who used the screening tool $(n=694)$ by location and $(B)$ summary of active provider $(\mathrm{N}=1316)$ screening utilisation categorised between 10 April 2018 and 8 December 2019. that aims to align social needs screening implementation across the health system and has support from health system leadership. This new objective includes a unified target, an annual assessment of every patient for social needs and support for specific roles of clinical team members based on best practices. In addition, we have redoubled efforts to provide clinical teams with feedback and useful, timely data through the development of revised dashboards. Finally, we are focusing on providing clinical teams with updated and improved social services resources to best support patients and their families that consider the limitations and barriers of addressing complex social needs in busy clinical practices. While we have observed many successes and opportunities for improvement in our health system's goal of addressing issues that affect our patients beyond clinical walls, it is clear that there is much work ahead.

\section{Author affiliations}

${ }^{1}$ Office of Community and Population Health, Montefiore Health System, Bronx, New York, USA

${ }^{2}$ Pediatrics, Albert Einstein College of Medicine, Bronx, New York, USA

${ }^{3}$ Family and Social Medicine, Albert Einstein College of Medicine, Bronx, New York, USA

${ }^{4}$ Hackensack Meridian Health Inc, Edison, New Jersey, USA

${ }^{5}$ MetroPlus Health Plan Inc, New York, New York, USA

${ }^{6}$ Montefiore Medical Group, Bronx, New York, USA

${ }^{7}$ Bronx Community Health Network Inc, Bronx, New York, USA

\section{Twitter Amanda Parsons @doctorheron}

Contributors KPF, CGH, NRH-H and ADR developed the initial concept for the study. $\mathrm{KPF}, \mathrm{CGH}, \mathrm{NRH}-\mathrm{H}, \mathrm{AF}, \mathrm{EC}$ and MR were involved in planning and initial drafting of manuscript. CGH conducted statistical analyses with input and feedback from KPF, $M R, E C$ and $A D R$. KPF and CGH provided the first manuscript draft. All authors (KPF, CGH, AF, NRH-H, AP, MR, EC, SH, TC and ADR) revised and contributed to the final version of the manuscript. KPF, CGH, MR and AF provided final revisions.

Funding This work was funded by the Doris Duke Charitable Foundation (grant 2018169) and the Agency for Healthcare Research and Quality (K12HS026396).

\section{Competing interests None declared.}

Patient consent for publication Not applicable.

Ethics approval The study was reviewed and approved by the Albert Einstein College of Medicine IRB (\#2017-8434).

Provenance and peer review Not commissioned; externally peer reviewed.

Data availability statement Data are available on reasonable request. No data are available. The dataset is from our institution's electronic health record and contains health protected information that cannot be shared without a data use agreement per our institution's policy.

Supplemental material This content has been supplied by the author(s). It has not been vetted by BMJ Publishing Group Limited (BMJ) and may not have been peer-reviewed. Any opinions or recommendations discussed are solely those of the author(s) and are not endorsed by BMJ. BMJ disclaims all liability and responsibility arising from any reliance placed on the content. Where the content includes any translated material, BMJ does not warrant the accuracy and reliability of the translations (including but not limited to local regulations, clinical guidelines, terminology, drug names and drug dosages), and is not responsible for any error and/or omissions arising from translation and adaptation or otherwise.

Open access This is an open access article distributed in accordance with the Creative Commons Attribution Non Commercial (CC BY-NC 4.0) license, which permits others to distribute, remix, adapt, build upon this work non-commercially, and license their derivative works on different terms, provided the original work is properly cited, appropriate credit is given, any changes made indicated, and the use is non-commercial. See: http://creativecommons.org/licenses/by-nc/4.0/. 
ORCID iD

Kevin P Fiori http://orcid.org/0000-0003-1370-7366

\section{REFERENCES}

1 Gottlieb L, Sandel M, Adler NE. Collecting and applying data on social determinants of health in health care settings. JAMA Intern Med 2013;173:1017-20.

2 National Academies of Sciences and Medicine E. Integrating Social Care into the Delivery of Health Care: Moving Upstream to Improve the Nation's Health [Internet]. Washington, DC: The National Academies Press, 2019. https://www.nap.edu/catalog/25467/ integrating-social-care-into-the-delivery-of-health-care-moving

3 Garg A, Toy S, Tripodis Y, et al. Addressing social determinants of health at well child care visits: a cluster RCT. Pediatrics 2015;135:e296-304.

4 Gottlieb L, Hessler D, Long D, et al. A randomized trial on screening for social determinants of health: the iScreen study. Pediatrics 2014;134:e1611-8

5 Gottlieb LM, Hessler D, Long D, et al. Effects of social needs screening and in-person service navigation on child health: a randomized clinical trial. JAMA Pediatr 2016;170:e162521.

6 Kangovi S, Mitra N, Grande D, et al. Evidence-Based community health worker program addresses unmet social needs and generates positive return on investment. Health Aff 2020;39:207-13.

7 Fiori KP, Rehm CD, Sanderson D, et al. Integrating social needs screening and community health workers in primary care: the community linkage to care program. Clin Pediatr 2020;59:547-56.

8 Gottlieb LM, Wing $\mathrm{H}$, Adler NE. A systematic review of interventions on patients' social and economic needs. Am J Prev Med 2017;53:719-29.

9 Pescheny JV, Pappas Y, Randhawa G. Facilitators and barriers of implementing and delivering social prescribing services: a systematic review. BMC Health Serv Res 2018;18:86.

10 Bickerdike L, Booth A, Wilson PM, et al. Social prescribing: less rhetoric and more reality. A systematic review of the evidence. BMJ Open 2017;7:e013384.

11 Beck AF, Cohen AJ, Colvin JD, et al. Perspectives from the Society for pediatric research: interventions targeting social needs in pediatric clinical care. Pediatr Res 2018;84:10-21.

12 Powell BJ, Waltz TJ, Chinman MJ, et al. A refined compilation of implementation strategies: results from the expert recommendations for implementing change (ERIC) project. Implementation Sci 2015;10:21.

13 Glasgow RE, Vogt TM, Boles SM. Evaluating the public health impact of health promotion interventions: the RE-AIM framework. Am J Public Health 1999;89:1322-7.
14 Fiori KP, Heller CG, Rehm CD, et al. Unmet social needs and No-Show visits in primary care in a US northeastern urban health system, 2018-2019. Am J Public Health 2020;110:S242-50.

15 Heller CG, Parsons AS, Chambers EC, et al. Social risks among primary care patients in a large urban health system. Am J Prev Med 2020;58:514-25.

16 Montefiore Medical Center $\mathrm{O}$ of $\mathrm{C}$ and $\mathrm{PH}$. Community service plan, 2016-2018, 2016. Available: http://www.montefiore.org/documents/ communityservices/Community-Service-Plan-MMC.pdf [Accessed 14 Feb 2017]

17 Chambers EC, Heller C, Fiori K, et al. Chronic pediatric health conditions among youth living in public housing and receiving care in a large hospital system in Bronx, NY. Glob Pediatr Health 2020;7:2333794X2097116.

18 Health Leads. Social Needs Screening Toolkit [Internet], 2016. Available: https://healthleadsusa.org/wp-content/uploads/2016/07/ Health-Leads-Screening-Toolkit-July-2016.pdf

19 Lindau ST. CommunityRx, an E-Prescribing system connecting people to community resources. Am J Public Health 2019;109:546-7.

20 Bellin E, Fletcher DD, Geberer N, et al. Democratizing information creation from health care data for quality improvement, research, and education-the Montefiore medical center experience. Acad Med 2010;85:1362-8.

21 Glasgow RE, McKay HG, Piette JD, et al. The RE-AIM framework for evaluating interventions: what can it tell us about approaches to chronic illness management? Patient Educ Couns 2001;44:119-27.

22 Address Geocoder- NYS GIS Program Office [Internet]. Available: https://gis.ny.gov/gisdata/inventories/details.cfm?DSID=1278 [Accessed 27 Aug 2019].

23 United States Census Bureau. American community survey, 20132017 American community survey 5-year estimates, table C17002; generated by colin D. Rehm; using American FactFinder.

24 Gold R, Bunce A, Cowburn S, et al. Adoption of social determinants of health EHR tools by community health centers. Ann Fam Med 2018;16:399-407.

25 Cottrell EK, Dambrun K, Cowburn S, et al. Variation in electronic health record documentation of social determinants of health across a national network of community health centers. Am J Prev Med 2019;57:S65-73.

26 Meyer D, Lerner E, Phillips A, et al. Universal screening of social determinants of health at a large US academic medical center, 2018. Am J Public Health 2020;110:S219-21.

27 LaForge K, Gold R, Cottrell E, et al. How 6 organizations developed tools and processes for social determinants of health screening in primary care: an overview. J Ambul Care Manage 2018;41:2-14. 